\title{
Erratum: Magnetic-confinement fusion
}

J. Ongena, R. Koch, R. Wolf and H. Zohm

Nature Physics 12, 398-410 (2016); published online 3 May 2016; corrected after print 16 June 2016.

In the version of this Review Article originally published, it was not acknowledged that Fig. 3a is courtesy of C. Brandt, IPP. This has been corrected in the online versions 16 June 2016. 